\title{
High-order ionospheric effects on electron density estimation from Fengyun-3C GPS radio occultation
}

\author{
Junhai $\mathbf{L i}^{1,2}$ and Shuanggen Jin ${ }^{1,3}$ \\ ${ }^{1}$ Shanghai Astronomical Observatory, Chinese Academy of Sciences, Shanghai 200030, China \\ ${ }^{2}$ University of Chinese Academy of Sciences, Beijing 100049, China \\ ${ }^{3}$ Department of Geomatics Engineering, Bulent Ecevit University, Zonguldak 67100, Turkey \\ Correspondence to: Shuanggen Jin (sgjin@ shao.ac.cn, sg.jin@yahoo.com)
}

Received: 11 November 2016 - Revised: 26 February 2017 - Accepted: 1 March 2017 - Published: 15 March 2017

\begin{abstract}
GPS radio occultation can estimate ionospheric electron density and total electron content (TEC) with high spatial resolution, e.g., China's recent Fengyun-3C GPS radio occultation. However, high-order ionospheric delays are normally ignored. In this paper, the high-order ionospheric effects on electron density estimation from the Fengyun-3C GPS radio occultation data are estimated and investigated using the NeQuick2 ionosphere model and the IGRF12 (International Geomagnetic Reference Field, 12th generation) geomagnetic model. Results show that the high-order ionospheric delays have large effects on electron density estimation with up to $800 \mathrm{el} \mathrm{cm}^{-3}$, which should be corrected in high-precision ionospheric density estimation and applications. The second-order ionospheric effects are more significant, particularly at $250-300 \mathrm{~km}$, while third-order ionospheric effects are much smaller. Furthermore, the high-order ionospheric effects are related to the location, the local time, the radio occultation azimuth and the solar activity. The large high-order ionospheric effects are found in the low-latitude area and in the daytime as well as during strong solar activities. The second-order ionospheric effects have a maximum positive value when the radio occultation azimuth is around $0-20^{\circ}$, and a maximum negative value when the radio occultation azimuth is around -180 to $-160^{\circ}$. Moreover, the geomagnetic storm also affects the high-order ionospheric delay, which should be carefully corrected.
\end{abstract}

Keywords. Ionosphere (ionosphere-magnetosphere interactions; solar radiation and cosmic ray effects) - radio science (remote sensing)

\section{Introduction}

GPS has been widely used in positioning, navigation and timing (PNT) as well as remote sensing (Wu et al., 2010; Najibi and Jin, 2013; Jin et al., 2014a). When the signal transmitted by GPS satellites propagates through the Earth's ionosphere and lower atmosphere, it will be delayed due to the atmosphere refraction (Jin et al., 2004, 2007, 2009). Nowadays, GPS can monitor the atmosphere and ionosphere with lots of advantages such as low cost, high precision, high temporal and spatial resolution, and all-weather and all-time observations (Afraimovich et al., 2010; Jin et al., 2011, 2015, 2016); this particularly applies to space-borne GPS radio occultation (RO) (Jin et al., 2014a). Currently, there are a number of GPS radio occultation missions, e.g., CHAMP (CHAllenging Minisatellite Payload) and COSMIC (Constellation Observing System for Meteorology, Ionosphere, and Climate), which can estimate the electron density and total electron content (TEC) in the ionosphere using the Abel transformation under the assumptions of spherical symmetry and straight-line propagation. However, only the first-order ionospheric delay is normally considered and the second- or higher-order ionospheric effects are ignored in GPS applications (Jin et al., 2006, 2014b, c). Therefore, the secondand higher-order ionospheric delays are involved in the inverted results. Previous studies showed large effects of highorder ionospheric delays on GPS positioning and applications (Hoque and Jakowski, 2008). For example, Wang et al. (2014) estimated the second-order ionospheric effect on the GPS positioning using the measured electron density and found the maximum second-order ionospheric delay error with about $0.6,0.8$ and $0.6 \mathrm{~cm}$ for L1 signals at the 
zenith, the north and north $10^{\circ}$ elevation angles, respectively. Hoque and Jakowski (2010) assessed the secondorder ionospheric effects on the GPS radio occultation data and showed the ionospheric effects with about 0.7 TECU $\left(1 \mathrm{TECU}=10^{16} \mathrm{el} \mathrm{m}^{-2}\right)$ on TEC estimation. An (2015) analyzed the second-order ionospheric effects on the atmosphere and found a second-order residual error of the excess phase at the centimeter level, which may lead to a great effect on the atmosphere parameter inversion.

Recently, China's Fengyun-3C was launched on 23 September 2013, which is the third satellite in China's second-generation series of polar-orbiting weather satellites. One of Fengyun-3C payloads is the GNSS (Global Navigation Satellite System) occultation sounder (GNOS), which will retrieve atmospheric parameters and the electron density for atmospheric and ionospheric studies. In this paper, the second- and third-order ionospheric effects on the ionospheric parameter estimation from Fengyun-3C GPS radio occultation data are estimated and investigated. In Sect. 2, the theory and method of the second- and third-order ionospheric delay estimation are introduced, the secondand third-order ionospheric effects are presented in Sect. 3, a case study of high-order ionospheric effects during the geomagnetic storm is presented in Sect. 4, and finally conclusions are given in Sect. 5.

\section{Methodology and data}

\subsection{High-order ionospheric delays}

The GPS signal is delayed when propagating through the ionosphere and the atmosphere. In GPS radio occultation data processing, the atmospheric delay or the excess phase can be written as follows (Jin et al., 2014a):

$\Delta L=L-\rho=\int\left(n_{\text {neu }}+n_{\text {ion }}\right) \mathrm{d} l-\rho$,

where $\Delta L$ is the excess carrier phase (in meters), $L$ is the phase measurement (in meters), $\rho$ is the geometric distance between the GPS satellite and the receiver on the low earth orbit (LEO) satellite, $n_{\text {neu }}$ is the refractive index of the neutral atmosphere, and $n_{\text {ion }}$ is the refractive index of the ionosphere. The ionospheric refractive index $n_{\text {ion }}$ is affected by the electron density and the intensity of the geomagnetic field along the signal ray path, which can be expressed using the Appleton-Hartree formula (Kashcheyev et al., 2012):

$$
\begin{aligned}
& n_{\text {ion }}^{2}=1-\frac{2 X(1-X)}{2(1-X)-Y_{t}^{2} \pm \sqrt{Y_{t}^{4}+4 Y_{l}^{2}(1-X)^{2}}}, \\
& X=\frac{e^{2}}{4 \pi^{2} \varepsilon_{0} m} \frac{N_{\mathrm{e}}}{f} ; Y=\frac{e}{2 \pi m} \frac{B_{0}}{f} ; Y_{t}=Y \sin \theta, Y_{l}=Y \cos \theta,
\end{aligned}
$$

where $\theta$ is the angle between the geomagnetic field vector and the signal propagation direction, $B_{0}$ is the intensity of the geomagnetic field, $N_{\mathrm{e}}$ is the electron density, $f$ is the frequency of the electromagnetic wave, $m$ is the electronic mass, $\varepsilon_{0}$ is the dielectric constant, and $e$ is the electron charge.

Simplifying Eq. (2), it can be written as follows:

$n_{\text {ion }}=1-\frac{1}{2} X-\frac{1}{2} X Y \cos \theta-\frac{1}{4} X\left[\frac{1}{2} X+Y^{2}(1+\cos \theta)\right]$.

The ionospheric delay of the phase measurement is expressed as (Morton et al., 2009)

$$
\begin{aligned}
& I_{\phi}=\int n_{\mathrm{ion}} \mathrm{d} l=-\frac{q}{f^{2}}-\frac{s}{2 f^{3}}-\frac{r}{3 f^{4}}, \\
& q=\frac{C_{x}}{2} \int N_{\mathrm{e}} \mathrm{d} l, s=C_{x} C_{y} \int N_{\mathrm{e}} B_{0} \cos \theta \mathrm{d} l, r=r_{1}+r_{2}+r_{3}, \\
& r_{1}=\frac{3 C_{x}^{2}}{8} \int N_{\mathrm{e}}^{2} \mathrm{~d} l, r_{2}=\frac{3 C_{x} C_{y}^{2}}{2} \int N_{\mathrm{e}} B_{0}^{2} \cos ^{2} \theta \mathrm{d} l, \\
& r_{3}=\frac{3 C_{x} C_{y}^{2}}{4} \int N_{\mathrm{e}} B_{0}^{2} \mathrm{~d} l, \\
& C_{x}=\frac{e^{2}}{4 \pi^{2} \varepsilon_{0} m}, C_{y}=\frac{e}{2 \pi m} .
\end{aligned}
$$

The second term in Eq. (5) is the second-order ionospheric delay, and the third term is the third-order ionospheric delay. The second- and third-order ionospheric delays are added into the carrier phase observations and the following equations can be obtained:

$$
\begin{aligned}
& L_{1}=\rho-N_{1} \lambda_{1}-\frac{40.3}{f_{1}^{2}} \int N_{\mathrm{e}} \mathrm{d} l-\operatorname{ion}_{1}^{2}-\operatorname{ion}_{1}^{3} \\
& L_{2}=\rho-N_{2} \lambda_{2}-\frac{40.3}{f_{2}^{2}} \int N_{\mathrm{e}} \mathrm{d} l-\operatorname{ion}_{2}^{2}-\operatorname{ion}_{2}^{3},
\end{aligned}
$$

where $\lambda_{i}$ is the wavelength of the signal, $N_{i}$ is the ambiguity, $\operatorname{ion}_{i}^{2}$ is the second-order ionospheric delay, ion $_{i}^{3}$ is the thirdorder ionospheric delay, and the subscript $i$ is the frequency 1 and 2 . Then we can get the TEC using the dual-frequency observations:

$$
\begin{aligned}
\mathrm{TEC} & =\int N_{\mathrm{e}} \mathrm{d} l \\
& =\frac{f_{1}^{2} f_{2}^{2}\left(L_{1}-L_{2}+N_{1} \lambda_{1}-N_{2} \lambda_{2}\right)}{40.3\left(f_{1}^{2}-f_{2}^{2}\right)} \\
& +\frac{f_{1}^{2} f_{2}^{2}\left(\mathrm{ion}_{1}^{2}+\mathrm{ion}_{1}^{3}-\mathrm{ion}_{2}^{2}-\mathrm{ion}_{2}^{3}\right)}{40.3\left(f_{1}^{2}-f_{2}^{2}\right)} .
\end{aligned}
$$

The second item in the left of Eq. (10) is called the high-order ionospheric residual TEC.

The measured electron density is normally proportional to the electron density derived from the model, so we can use 
the measured TEC to modify the ionospheric effects as follows:

$$
\begin{aligned}
& \tilde{I}_{2}=\frac{\mathrm{TEC}_{\text {measured }}}{\mathrm{TEC}_{\text {mod el }}} I_{2} \\
& \widetilde{I}_{3} \approx \frac{\text { TEC }_{\text {measured }}^{2}}{\mathrm{TEC}_{\text {mod el }}^{2}} I_{3}
\end{aligned}
$$

where $\widetilde{I}_{2}$ and $\widetilde{I}_{3}$ are the modified second-order and thirdorder ionospheric effects, respectively, and the $I_{2}$ and $I_{3}$ are the second-order and third-order ionospheric effects from the model, respectively. The primary term in the third-order ionospheric effect is related to the squared electron density (Eq. 5), so we use the squared TEC as the coefficient of proportionality.

\subsection{Ionospheric delay and geomagnetic field}

The ionospheric delay along the signal path is related to the signal trajectory between the initial and end points. Born and Wolf (1999) gave the formula to describe the signal propagation in the non-vacuum space:

$$
\frac{d}{\mathrm{~d} s}\left(n \frac{d \boldsymbol{r}}{\mathrm{d} s^{2}}\right)=n \frac{d^{2} \boldsymbol{r}}{\mathrm{d} s^{2}}+\frac{\mathrm{d} n}{\mathrm{~d} s} \frac{d \boldsymbol{r}}{\mathrm{d} s}=\nabla n,
$$

where $\boldsymbol{r}$ is the Cartesian coordinate vector of the signal trajectory, $s$ is the length of the signal trajectory, $n$ is the refractive index and $\nabla n$ is the derivative of refractive index. From Eq. (12), we can derive the second-order derivative of $\boldsymbol{r}$ :

$$
\frac{d^{2} \boldsymbol{r}}{\mathrm{d} s^{2}}=\frac{1}{n}\left(\nabla n-\frac{\mathrm{d} n}{\mathrm{~d} s} \frac{d \boldsymbol{r}}{\mathrm{d} s}\right)
$$

The $\boldsymbol{r}$ has the three components along the signal trajectory in the Cartesian coordinate system $(x, y, z), \nabla n$ is the derivative of refractive index in $X, Y, Z$ directions. A fourth-order Runge-Kutta technique is applied to follow the trajectory of the signal propagation in three direction components.

In addition, a 3-D ionospheric model and geomagnetic model are also needed to get the electron density and the intensity of the geomagnetic field along the signal path. Here, the 3-D ionospheric NeQuick2 model is used (Nava et al., 2008). The NeQuick2 model is particularly designed for transionospheric propagation applications by the International Centre for Theoretical Physics (ICTP). The basic variables of this model are position, time and solar flux, and the output is the electron density at the given time and position. In addition, we use the IGRF12 (International Geomagnetic Reference Field, 12th generation) (Thébault et al., 2015) to get the intensity of the geomagnetic field. The IGRF model consists of sets of spherical harmonics coefficients derived from a large number of observable data. It can provide the intensity and the northward, eastward and vertical components of the geomagnetic field, which can be used to calculate the secondand third-order ionospheric delay with Eq. (5).

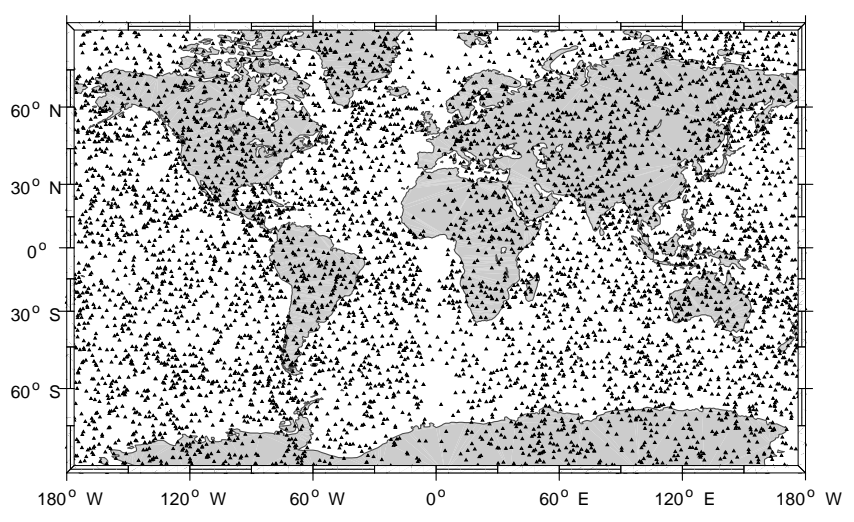

Figure 1. Fengyun-3C radio occultation point distribution from 1 to 30 September 2014.

\subsection{Observation data}

The Fengyun-3C realizes all-weather, multispectral, quantitative and 3-D observation of the global atmosphere for monitoring disasters, the environment and climate change. The GNOS onboard Fengyun-3C can retrieve atmospheric parameters for atmospheric monitoring and weather forecasting and monitor the electron density for ionospheric studies. The GNOS has four occultation antennas to receive GPS signals, which produce more than 100 ionospheric occultation events and 500 atmospheric occultation events (Bi et al., 2012). The Fengyun-3C GPS radio occultation data are available at the Fengyun Satellite Data Center website (http://satellite.nsmc.org.cn). We can get the radio occultation excess phase observed by the GNOS on the Fengyun$3 \mathrm{C}$. Here, the Fengyun-3C radio occultation data used are from 1 to 30 September 2014 with almost 7000 ionospheric sounding profiles (Fig. 1).

In order to show the high-order ionospheric effects on Fengyun-3C ionospheric sounding globally, the selected occultation points should have a good spatial and temporal distribution. After checking the data, we found that the data are evenly distributed in latitudinal direction and local time (Fig. 2).

In addition, the solar activity is quiet during this period. Since the Fengyun Satellite Data Center just provides the excess phase data, the TEC is calculated from the excess phase data. As we mentioned above, the electron density along the signal path is assumed to satisfy the Chapman function. We use the maximum electron density of the F2 layer and its corresponding height to calculate the TEC along the signal path. 
(a)

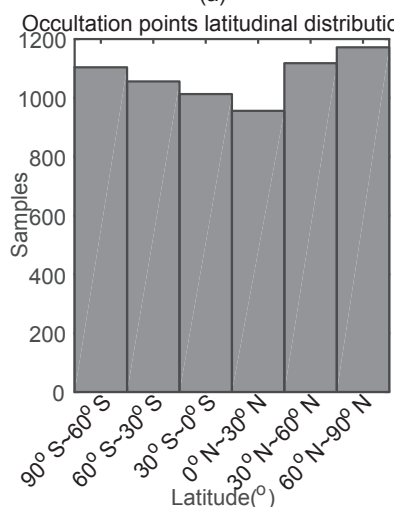

(b)

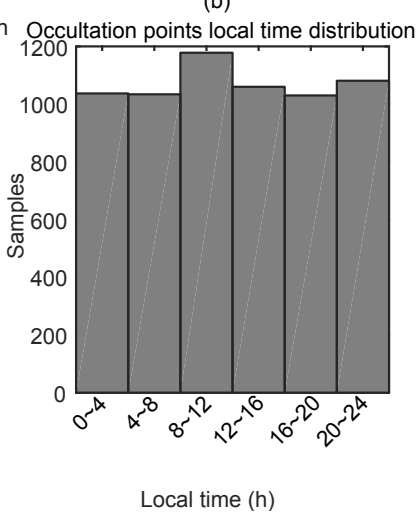

Figure 2. Fengyun-3C occultation point distribution with the latitude (a) and local time (b).
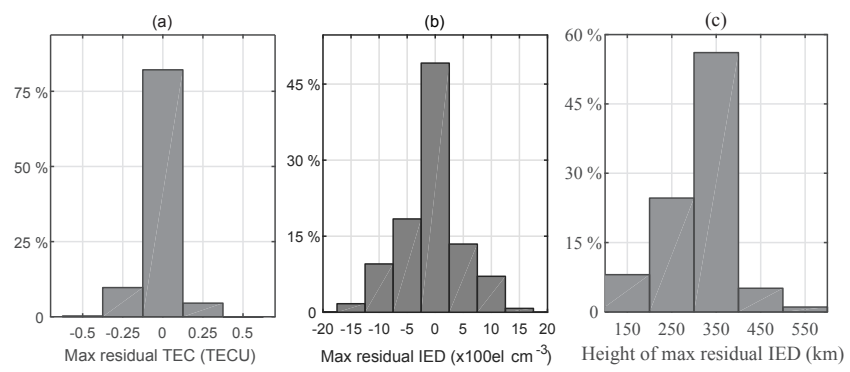

Figure 3. Histogram of maximum residual TEC along the signal path (a), residual electron density (b) and the heights of the maximum residual electron density (c).

\section{Results and analysis}

\subsection{High-order ionospheric effects}

\subsubsection{Second-order ionospheric effects}

The second-order ionospheric effects are estimated from 6420 profiles of the Fengyun-3C GPS ionospheric radio occultation. The maximum residual TEC and electron density from the second-order ionosphere effects are shown in Fig. 3. Almost $80 \%$ of maximum residual TEC are located between $-0.25 \mathrm{TECU}$ and $0.25 \mathrm{TECU}$, and about $80 \%$ of the maximum residual electron densities are located between -500 and $500 \mathrm{el} \mathrm{cm}^{-3}$. Some second-order ionospheric effects even exceed 5\% (e.g., at 07:44 12 September 2014, 16:14 on 14 September 2014 and 17:27 on 20 September 2014). Therefore, the second-order ionospheric effect on the ionospheric electron density estimation should be considered and corrected.

We also analyze the height of maximum residual electron density. Most heights of maximum residual electron density are around $250-350 \mathrm{~km}$, which is the range of the peak height of layer F2, indicating that the heights of the line of sight (LOS) tangent point around $250-350 \mathrm{~km}$ have a greater

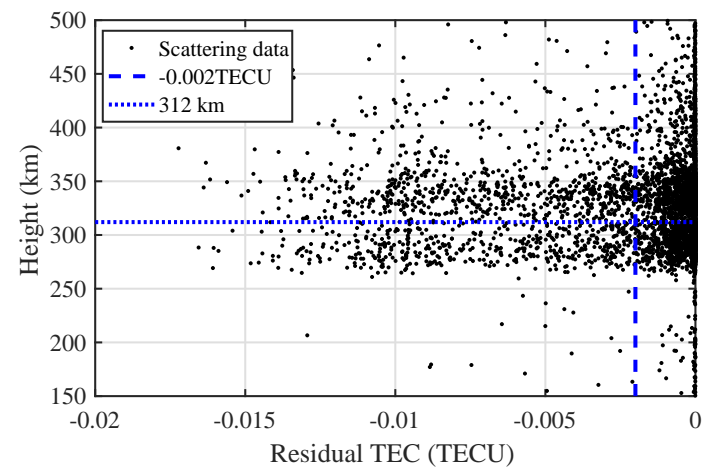

Figure 4. Third-order ionospheric residual TEC with its LOS tangent point heights.

second-order ionospheric effect. Therefore, the second-order ionospheric effects at these altitudes are larger than others because these signals have a longer propagation path in the ionosphere.

\subsubsection{Third-order ionospheric effects}

Furthermore, the third-order ionospheric effects on the ionospheric electron density from Fengyun-3C GPS radio occultation are obtained in Fig. 4. Most maximum residual TECs of the third-order ionospheric effects along the signal path are below $0.015 \mathrm{TECU}$, and all of them are less than 0.02 TECU, while the second-order ionospheric effect is about $0.5 \mathrm{TECU}$. So the third-order ionospheric effects are about 30 times weaker than the second-order effects. The errors of secondorder ionospheric effects are less than $1 \%$ in general and less than $10 \%$ in some special conditions, while the errors of third-order ionospheric effects are less than $0.4 \%$ even in some special conditions. Therefore, the third-order ionospheric effects in the occultation data processing can be ignored. The LOS tangent point heights of maximum thirdorder ionospheric residual TEC are shown in Fig. 4. The LOS tangent point heights of maximum third-order ionospheric residual TEC are located between 250 and $350 \mathrm{~km}$, which is similar to the second-order ionospheric effect characteristics mentioned in Sect. 3.1.1.

\subsection{Latitudinal variations of high-order ionospheric effects}

As we know, the ionospheric electron density reaches the peak value at the both sides of magnetic equator, and the ionospheric electron density in the high-latitude area is smaller than that in the low-latitude area. So we categorize the residual TEC along the signal path by the latitude of the occultation tangent point and map it with the RO azimuth. In Fig. 5, the blue markers lie above the green markers and the green markers lie above the red markers. The high-order ionospheric effects are determined by the location of the sig- 


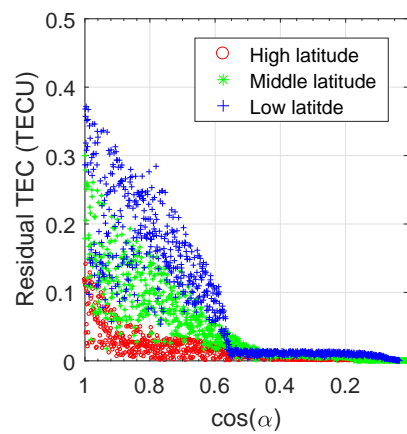

(a) Southern Hemisphere

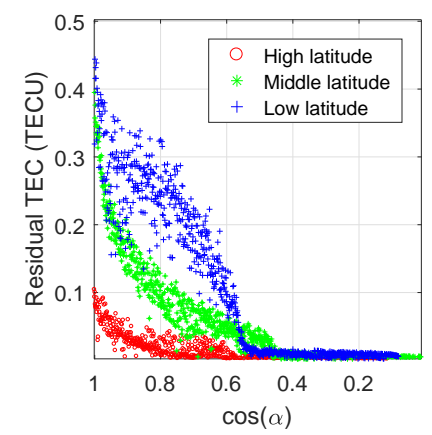

(b) Northern Hemisphere

Figure 5. Residual TEC along the signal path with tangent point at $0-30^{\circ}$ (blue), $30-60^{\circ}$ (green) and $60-90^{\circ}$ (red) in the Southern Hemisphere (a) and in the Northern Hemisphere (b). The $x$ axis is the absolute cosine value of the RO azimuth, and the $y$ axis is the absolute value of residual TEC.
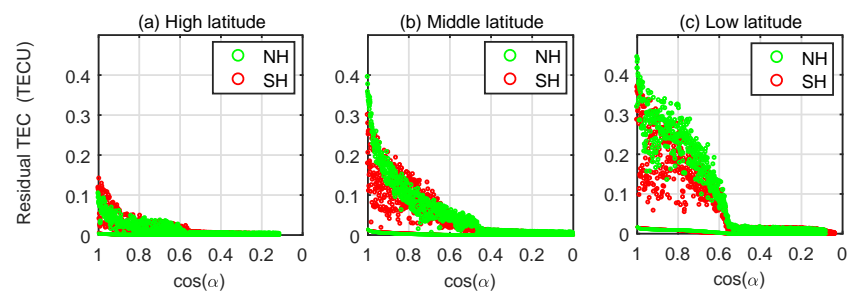

Figure 6. Residual TEC along the signal path with tangent point in the high-latitude area (a), middle-latitude area (b) and low-latitude area (c) in the Southern Hemisphere ( $\mathrm{SH}$ ) (red circles) and the Northern Hemisphere (NH) (green circles).

nal path tangent point and the RO azimuth in Eq .(5). If we fix the RO azimuth, we find that the high-order ionospheric effects in the low-latitude area are more significant than those in the high-latitude area.

Furthermore, we categorize residual TECs of the highorder ionospheric effects by the hemisphere and latitude of the signal path tangent point. From Fig. 6, we can see that the green circles lie above the red circles, especially in panels $b$ and $c$, which means that in the same latitude area, the residual TEC in the Northern Hemisphere is larger than that in the Southern Hemisphere. As we know, the electron density distributes in symmetry to the magnetic equator, and the geomagnetic equator lies on the northern side of the geodetic equator (Rastogi, 1960; Kil et al., 2011), so in some places, the double peak values of electron density are both in the low-latitude area of the Northern Hemisphere. Therefore, if we fix the latitude value, the high-order ionospheric effects are more obvious in the Northern Hemisphere.

\subsection{Local time variations of high-order ionospheric effects}

The relationship between the local time at the LOS tangent point and the high-order ionospheric effects are discussed be-

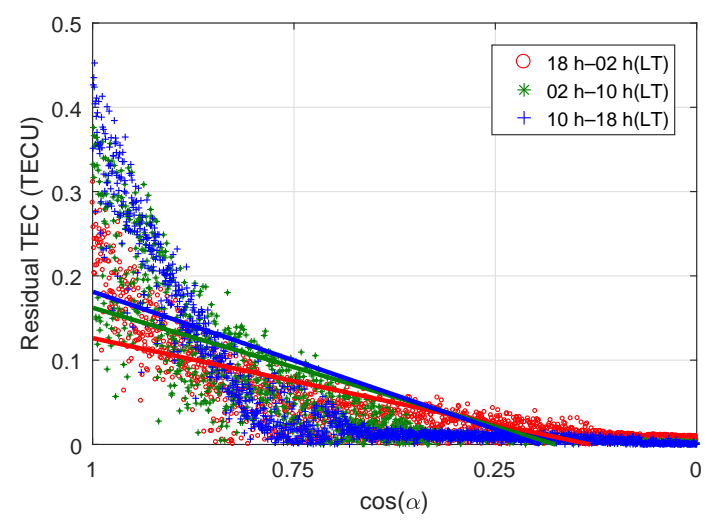

Figure 7. High-order ionospheric residual TEC along the signal path during 18:00-02:00 LT (red circles), 02:00-10:00LT (green stars) and 10:00-18:00 LT (blue plus). The $x$ axis is the absolute cosine value of RO azimuth, and the $y$ axis is the absolute value of residual TEC. The lines are the average value of residual TEC in different RO azimuths.

cause the hour of sunlight is a key factor. There are more hours of sunlight when the occultation events occur between 10:00 and 18:00 LT (local time) while there are fewer hours of sunshine when the events occur between 18:00 and 02:00 (next day). We divide all high-order ionospheric residual TECs into three groups, whose local time is 10:00-18:00, 18:00-02:00 and 02:00-10:00.

The three groups of high-order ionospheric effects are presented with the RO azimuth in different colors (Fig. 7). From the distribution of the different colored markers and the lines, we can see the occultation events occurred between 10:00 and 18:00 LT have a more significant high-order ionospheric effect than those that occurred at another time. The reason is probably that the solar radiation can ionize the molecule in the ionosphere. The stronger the solar radiation is, the more molecules will be ionized. So the electron density in the ionosphere will increase after sunrise and decrease after sunset because of the solar radiation daily variation. In addition, the part around the tangent point is the main part along the signal path to produce the high-order ionospheric delay because this part actually propagates into the ionosphere. So we can see that the high-order ionospheric effect is more obvious in the local daytime of the occultation tangent point.

\subsection{High-order ionospheric effects with the RO azimuth}

The relationship between the high-order ionospheric effects and the radio occultation azimuth is further discussed. In this paper, the RO azimuth is the angle between the signal propagation direction in the occultation plane and the true north at the occultation point (Qu et al., 2015). When the signal propagates from the north to the south, the azimuth is $180^{\circ}$ (see $\alpha$ in Fig. 8). 


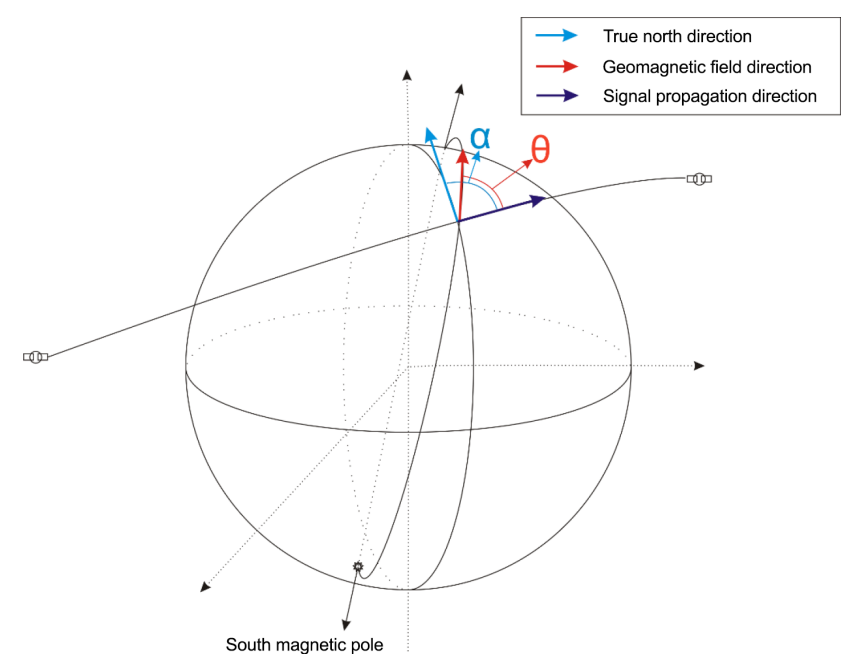

Figure 8. Sketch of the radio occultation azimuth.

\subsubsection{Second-order ionospheric effects}

The second-order ionospheric residual electron density ( $y$ axis) is estimated with the RO azimuth ( $x$ axis). The positive residual electron density centralizes in the RO azimuths between -50 and $50^{\circ}$, and the negative residual electron density centralizes in the RO azimuths between -120 and $120^{\circ}$. Moreover, the residual electron density reaches its largest positive value when the RO azimuth is around $0^{\circ}$ and its largest negative value when the $\mathrm{RO}$ azimuth is around $\pm 180^{\circ}$. From the Appleton-Hartree equation, we know that the second-order ionospheric delay is caused by the refraction when the signal propagates in the ionosphere and the refractive index is determined by electron density, the geomagnetic field vector along the signal path and the signal propagation direction. Therefore, the angle between the signal propagation and the geomagnetic field direction significantly affects the second-order ionospheric delay estimation. Since the RO azimuth is more easily got than the angle mentioned above, the relationship between the second-order ionospheric delay and the RO azimuth is established to assess the ionospheric effects. From Fig. 9, when the RO azimuth is around 0 and $-180^{\circ}$, the second-order ionospheric effects are more significant. The initial phase in the cosine function mentioned above may be connected with the angle between the true North Pole and the geomagnetic true pole. Because the $\theta$ in the Appleton-Hartree equation refers to the geomagnetic north pole while the $\mathrm{RO}$ azimuth $\alpha$ refers to the true North Pole, there is a difference between the geomagnetic true pole and the true North Pole.

\subsubsection{Third-order ionospheric effects}

Furthermore, we estimate the relationship between the thirdorder residual TEC along the signal path and the RO azimuth and find that the third-order ionospheric effects are different

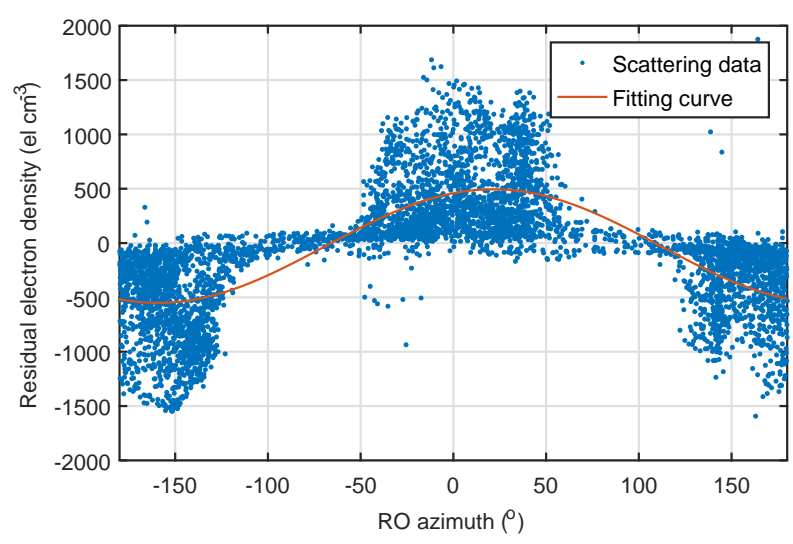

Figure 9. The relationship between second-order ionospheric residual electron density and RO azimuth.

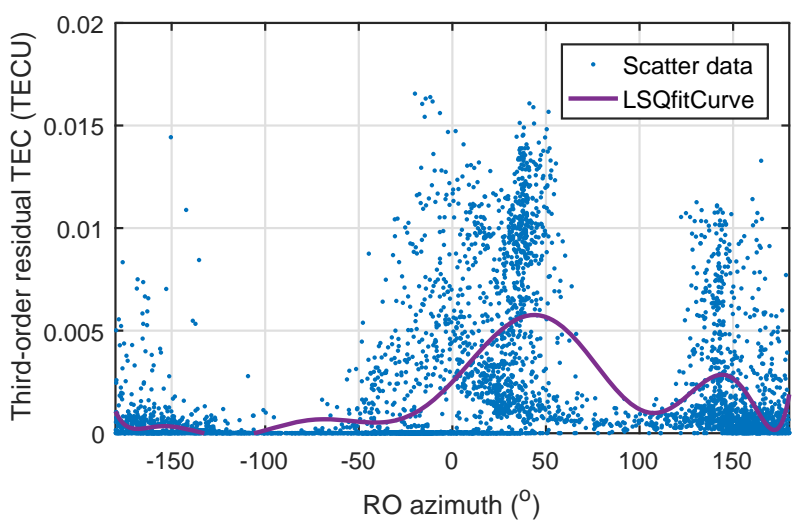

Figure 10. The relationship between third-order ionospheric residual electron density and RO azimuth.

from the second-order one. Because all the residual TECs are positive, we cannot find any relationships with the RO azimuth. So the third-order ionospheric effects are RO azimuthindependent.

\subsection{High-order ionospheric effects with solar activities}

The solar radio flux at $10.7 \mathrm{~cm}(\mathrm{~F} 10.7 \mathrm{~cm})$ is an indicator of the solar activity and correlated well with the sunspot number. The indices show the solar activity condition varying from 50 to above 300 during a solar cycle. Here, we discuss high-order ionospheric effects under different solar activities, e.g., 70, 120 and 193, of F10.7 cm to indicate the weak, normal and strong solar activities, which are input variables for the NeQuick2 model. Two events are selected to simulate the high-order ionospheric effects in the same area with opposite azimuths. We can see the residual electron density becomes larger as the F10.7 cm index increases (Fig. 11b and d). The residual electron density increases more than 3 times in the strong solar activity condition than in the quiet solar activity condition and by about 2 times the normal solar activity con- 

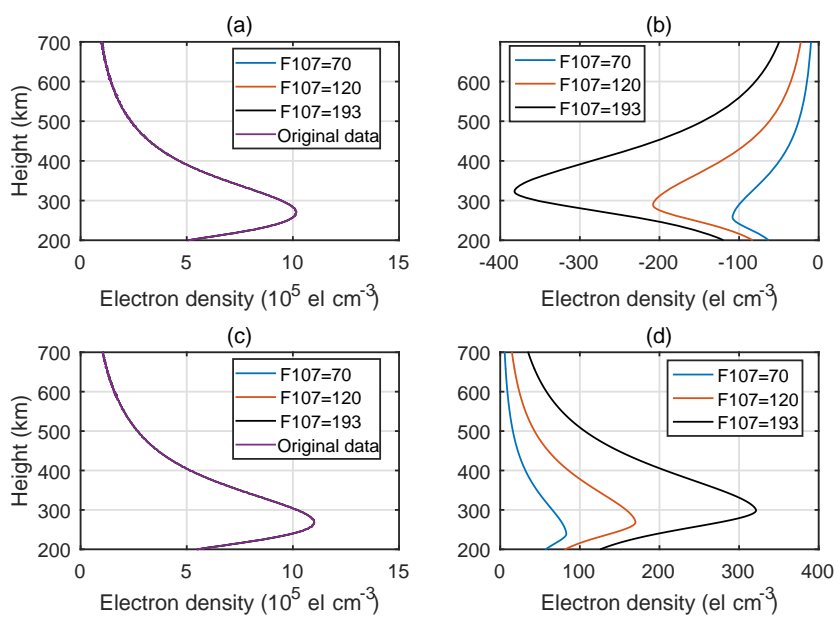

Figure 11. Panels (a) and (c) are profiles of the ionospheric electron density; (b) and (d) are the high-order ionospheric effects with different $\mathrm{F} 10.7 \mathrm{~cm}$ indices.

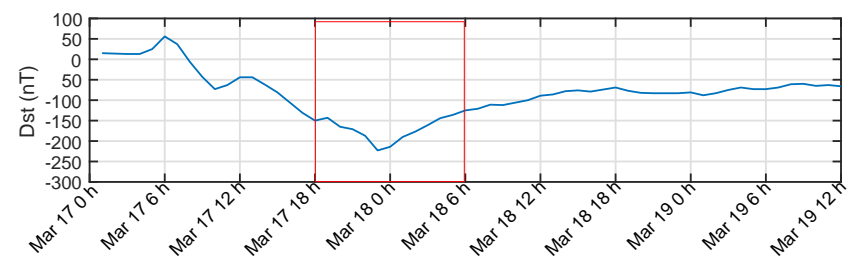

Figure 12. Dst index from 17 to 19 March 2015.

dition. The F10.7 cm indices in September 2014 are about 120. In this solar activity condition, some high-order ionospheric effects have exceeded $1 \%$. So the high-order ionospheric effects cannot be simply ignored without considering the space weather condition. It would lead to a significant error in electron density estimation.

\section{High-order ionospheric effects during the geomagnetic storm}

A geomagnetic storm is a temporary disturbance of the geomagnetic field, which will induce ionospheric variations and possible high-order ionospheric delays. Here, the high-order ionospheric effects are investigated during the intense geomagnetic storm which occurred on 17 March 2015 with a maximum disturbance storm time index (Dst) of $-223 \mathrm{nT}$ (Jin et al., 2017).

We select nine radio occultation events during the geomagnetic storm for about 06:00. The nine profiles are presented in Fig. 13 and we find the profile curve at 00:37 on 17 March is smooth because there is no geomagnetic storm effect at that time, while from 06:04 on 17 March, the curve is not smooth anymore. The geomagnetic storm began to disturb the ionosphere, and the receiver could not track the signal well anymore. Furthermore, the disturbed ionosphere has no
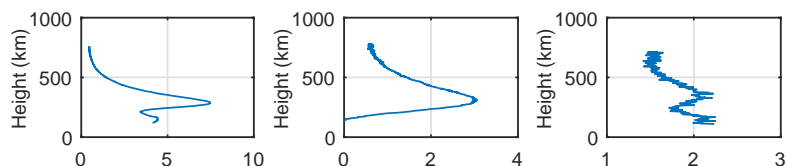

Electron density $\left(10^{5} \mathrm{el} \mathrm{cm}^{-3}\right)$ Electron density $\left(10^{5} \mathrm{el} \mathrm{cm}^{-3}\right)$ Electron density $\left(10^{5} \mathrm{el} / \mathrm{cm}^{-3}\right)$
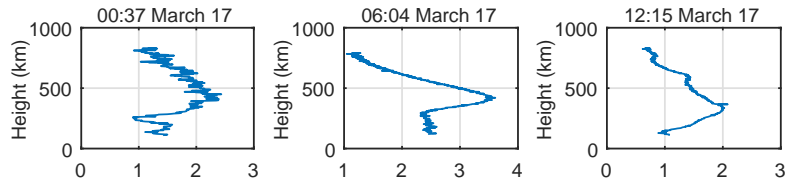

Electron density $\left(10^{5} \mathrm{el} \mathrm{cm}^{-3}\right)$ Electron density $\left(10^{5} \mathrm{el} \mathrm{cm}^{-3}\right)$ Electron density $\left(10^{5} \mathrm{el} \mathrm{cm}^{-3}\right)$
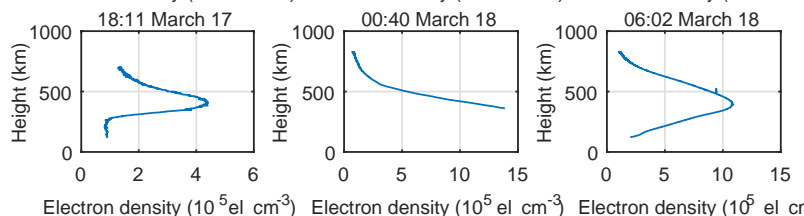

12:16 March 18

18:09 March 18

00:59 March 19

Figure 13. The profiles of ionospheric electron density during the different periods of the geomagnetic storm.

symmetrical features. Therefore, the spherical symmetrical assumption is not suitable in electron density estimation and the profile at 12:15 and 18:11 on 17 March is not reasonable. After 06:02 on 18 March, the geomagnetic storm ended, and the profile began to return to normal.

Furthermore, the high-order ionospheric effect is also estimated during the geomagnetic storm. Because the electron density in the ionosphere experiences a great disturbance during the geomagnetic storm, the ionosphere model cannot present the real ionospheric activities very well. Here, we use the measured TEC to calibrate the high-order ionospheric delay and find no big difference before the geomagnetic storm in the high-order ionospheric residual electron density between the original data (blue line in Fig. 14a, left panel) and calibrated data (red line in Fig. 14a, right panel). By contrast, during the geomagnetic storm, the high-order ionospheric effect estimation is not valid when we use the ionosphere model directly. Like the blue line in Fig. 14b (right panel), the residual electron density has both positive and negative values in one profile. After using measured TEC calibration, all the residual electron density has the same sign in one profile.

After the geomagnetic storm, we also estimate the highorder ionospheric effect and calibrate it with the measured TEC. One can conclude that the calibrated one is closer to the real condition because the peak value of the residual electron density after calibrating is closer to the peak value of the electron density in the F2 layer, which agrees with the conclusion we mentioned in Sect. 3.1. Because the geomagnetic storm was just over and the ionosphere had not recovered to the condition preceding the storm, there is a big difference between the original data and calibrated data of residual electron density. 
(a) Before the geomagnetic storm
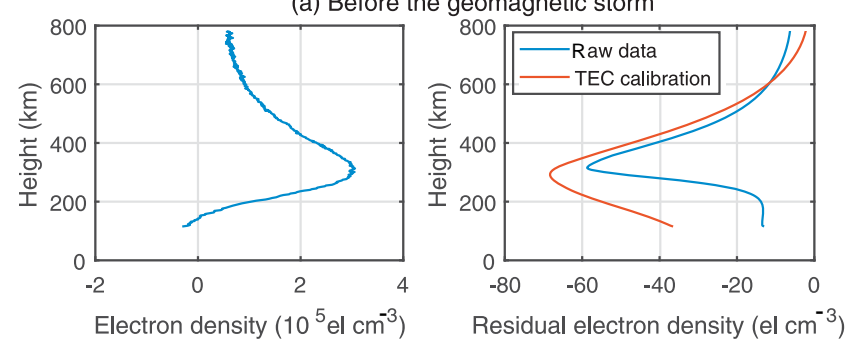

(b) During the geomagnetic storm
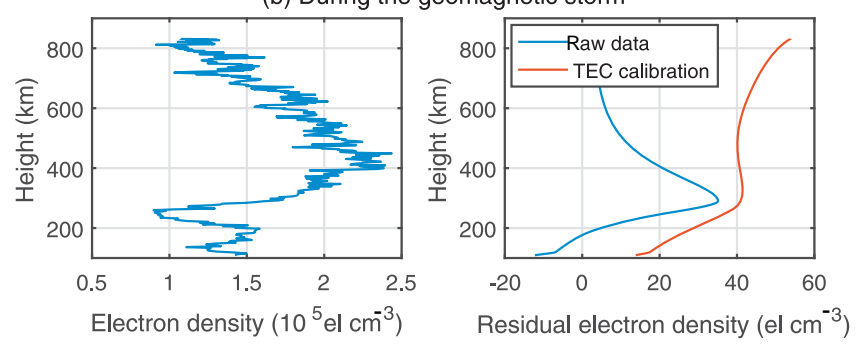

(c) After the geomagnetic storm
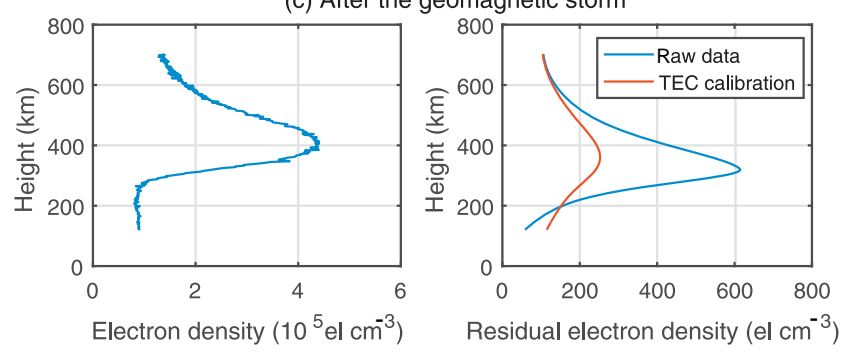

Figure 14. The profile of electron density (left panel) and its highorder ionospheric residual electron density (right panel) before the geomagnetic storm, during the geomagnetic storm and after the geomagnetic storm.

The results show that the geomagnetic storm also affects the high-order ionospheric effect estimation, and the characteristic of high-order ionospheric effect does not follow the quiet condition we present in Sect. 3. When there is a geomagnetic storm, the ionosphere is disturbed and the ionospheric model cannot present the real ionosphere condition. Therefore, the GPS receiver cannot track the signal correctly and cannot estimate a proper electron density or the highorder ionospheric effect.

\section{Conclusion}

In this paper, the NeQuick2 ionosphere model, IGRF12 geomagnetic model and the signal tracking technique are used to estimate and investigate the high-order ionospheric effects on Fengyun-3C electron density estimation. The second-order ionospheric effects are about $\pm 500 \mathrm{el} \mathrm{cm}^{-3}$, and some even exceed $\pm 1500 \mathrm{el} \mathrm{cm}^{-3}$ in the electron density estimation. Therefore, the second-order ionospheric effects cannot be ignored in precise ionospheric electron density estimation.
However, the third-order ionospheric effects are about 30 times weaker than the second-order ones, which can be ignored at current precisions. The occultation tangent point height of the peak value in the high-order ionospheric effect agrees with the height of the peak value of the electron density in the F2 layer. In addition, the high-order ionospheric effects are more obvious in the low-latitude tangent point area and in the daytime. Furthermore, the high-order ionospheric effect is correlated well with the RO azimuth. When the $\mathrm{RO}$ azimuth is around $0^{\circ}$ and $\pm 180^{\circ}$, the high-order ionospheric effect is more obvious, which cannot be ignored. Furthermore, the solar activity is also the main effect factor of the high-order ionospheric delay. During the strong solar activity, the high-order ionospheric effects will increase to 2 or 3 times the quiet period, so we must consider the highorder ionospheric effects on electron density estimation during the strong solar activity. Finally, the geomagnetic storm also affects the high-order ionospheric delay. During the geomagnetic storm, the ionospheric model cannot present the real ionosphere anymore, so the high-order ionospheric effect should be carefully estimated and corrected.

Data availability. The ionospheric electron density model NeQuick2 is from http://t-ict4d.ictp.it/nequick2/source-code (Nava et al., 2008).

Competing interests. The authors declare that they have no conflict of interest.

Acknowledgements. This work was supported by the National Natural Science Foundation of China (NSFC) Project (grant no. 11573052). Great appreciation is extended to the National Satellite Meteorological Center for providing the Fengyun-3C GPS radio occultation data.

The topical editor, K. Hosokawa, thanks the two anonymous referees for help in evaluating this paper.

\section{References}

Afraimovich, E., Ding, F., Kiryushkin, V., Astafyeva, E., Jin, S. G., and Sankov, V.: TEC response to the 2008 Wenchuan earthquake in comparison with other strong earthquakes, Int. J. Remote Sens., 31, 3601-3613, doi:10.1080/01431161003727747, 2010.

An, J., Du, Y. J., and Qu, X. C.: Analysis of second order ionospheric effects on atmospheric parameters estimation in radio occultation, Geomatics \& Information Science of Wuhan University, 40, 1440-1445, doi:10.13203/j.whugis20150228, 2015.

Born, M. and Wolf, E.: Principles of Optics: Elec- tromagnetic Theory of Propagation, Interference and Diffraction of Light, 7th edition, Cambridge University Press, New York, 985 pp., 1999. 
Bi, Y. M., Yang, Z. D., Zhang, P., Sun, Y. Q., Bai, W. H., and Du, Q. F.: An introduction to china fy3 radio occultation mission and its measurement simulation, Adv. Space Res., 49, 1191-1197, doi:10.1016/j.asr.2012.01.014, 2012.

Hoque, M. M. and Jakowski, N.: Estimate of higher order ionospheric errors in GNSS positioning, Radio Sci., 43, RS5008, doi:10.1029/2007RS003817, 2008.

Hoque, M. M. and Jakowski, N.: Higher order ionospheric propagation effects on GPS radio occultation signals, Adv. Space Res., 46, 162-173, doi:10.1016/j.asr.2010.02.013, 2010.

Jin, S. G., Wang, J., Zhang, H., and Zhu, W.: Real-time monitoring and prediction of the total ionospheric electron content by means of GPS observations, Chin. Astron. Astrophys., 28, 331337, doi:10.1016/j.chinastron.2004.07.008, 2004.

Jin, S. G. and Park, P.: Strain accumulation in South Korea inferred from GPS measurements, Earth Planets Space, 58, 529534, doi:10.1186/BF03351950, 2006.

Jin, S. G., Cho, J., and Park, J.: Ionospheric slab thickness and its seasonal variations observed by GPS, J. Atmos. Sol.-Terr. Phy., 69, 1864-1870, doi:10.1016/j.jastp.2007.07.008, 2007.

Jin, S. G., Luo, O. F., and Gleason, S.: Characterization of diurnal cycles in ZTD from a decade of global GPS observations, J. Geodesy., 83, 537-545, doi:10.1007/s00190-008-0264-3, 2009.

Jin, S. G., Feng, G. P., and Gleason, S.: Remote sensing using GNSS signals: current status and future directions, Adv. Space Res., 47, 1645-1653, doi:10.1016/j.asr.2011.01.036, 2011.

Jin, S. G., Cardellach, E., and Xie, F.: GNSS Remote Sensing: Theory, Methods and Applications, Springer, the Netherlands, ISBN13: 978-94-007-7481-0, 276 pp., 2014a.

Jin, S. G., Jin, R., and Li, J. H.: Pattern and evolution of seismoionospheric disturbances following the 2011 Tohoku earthquakes from GPS observations, J. Geophys. Res.-Space, 119, 79147927, doi:10.1002/2014JA019825, 2014b.

Jin, S. G. and Najibi, N.: Sensing snow height and surface temperature variations in Greenland from GPS reflected signals, Adv. Space Res., 53, 1623-1633, doi:10.1016/j.asr.2014.03.005, 2014c.

Jin, S. G., Occhipinti, O., and Jin, R.: GNSS ionospheric seismology: Recent observation evidences and characteristics, Earth-Sci. Rev., 147, 54-64, doi:10.1016/j.earscirev.2015.05.003, 2015.

Jin, S. G., Jin, R., and Li, D.: Assessment of BeiDou differential code bias variations from multi-GNSS network observations, Ann. Geophys., 34, 259-269, doi:10.5194/angeo-34-259-2016, 2016.
Jin, S. G., Jin, R., and Kutoglu, H.: Positive and negative ionospheric responses to the March 2015 geomagnetic storm from BDS observations, J. Geodesy., 91, doi:10.1007/s00190-0160988-4, 2017.

Kashcheyev, A., Nava, B., and Radicella, S. M.: Estimation of higher-order ionospheric errors in GNSS positioning using a realistic 3-D electron density model, Radio Science, 47, 49694997, doi:10.1029/2011RS004976, 2012.

Kil, H., Kwak, Y. S., Oh, S. J., Talaat, E. R., Paxton, L. J., and Zhang, Y.: The source of the longitudinal asymmetry in the ionospheric tidal structure, J. Geophys. Res.-Space, 116, 412-419, doi:10.1029/2011JA016781, 2011.

Morton, Y. T., Zhou, Q., and Frank, V. G.: Assessment of secondorder ionosphere error in GPS range observables using Arecibo incoherent scatter radar measurements, Radio Sci., 44, RS1002, doi:10.1029/2008RS003888, 2009.

Najibi, N. and Jin, S. G.: Physical reflectivity and polarization characteristics for snow and ice-covered surfaces interacting with GPS signals, Remote Sens., 5, 4006-4030, doi:10.3390/rs5084006, 2013.

Nava, B., Coïsson, P., and Radicella, S. M.: A new version of the NeQuick ionosphere electron density model, J. Atmos. Sol.-Terr. Phy., 70, 1856-1862, doi:10.1016/j.jastp.2008.01.015, 2008 (data available at: http://t-ict4d.ictp.it/nequick2/source-code).

Qu, X., Li, Z., An, J., and Ding, W.: Characteristics of second-order residual ionospheric error in gnss radio occultation and its impact on inversion of neutral atmospheric parameters, J. Atmos. Sol.Terr. Phy., 130-131, 159-171, 2015.

Rastogi, R. G.: Asymmetry between the F2, region of the ionosphere in the northern and southern hemispheres, J. Geophys. Res. Atmos., 65, 857-868, doi:10.1029/JZ065i003p00857, 1960.

Thébault, E., Finlay, C. C., and Beggan, C.: International Geomagnetic Reference Field: the 12th generation, Earth Planets Space, 67, 1-19, doi:10.1186/s40623-015-0228-9, 2015.

Wang, H., Wang, C., and Wang, J. X.: Global characteristics of the second-order ionospheric delay error using inversion of electron density profiles from COSMIC occultation data, Sci China-Phys. Mech. Astron., 57, 365-374, doi:10.1007/s11433-013-5376-y, 2014.

Wu, Y., Jin, S. G., Wang, Z., and Liu, J.: Cycle slip detection using multi-frequency GPS carrier phase observations: A simulation study, Adv. Space Res., 46, 144-149, doi:10.1016/j.asr.2009.11.007, 2010. 